\title{
Research Article \\ Effect of Mn Doping on Properties of CdS Quantum Dot-Sensitized Solar Cells
}

\author{
Tianxing Li, Xiaoping Zou, and Hongquan Zhou \\ Research Center for Sensor Technology, Beijing Key Laboratory for Sensor, Ministry of Education, \\ Key Laboratory for Modern Measurement and Control Technology, School of Applied Sciences, \\ School of Instrumentation Science and Optoelectronics Engineering, Beijing Information Science and Technology University, \\ Jianxiang Qiao Campus, Beijing 100101, China \\ Correspondence should be addressed to Xiaoping Zou; xpzou2005@gmail.com
}

Received 4 April 2014; Accepted 4 July 2014; Published 17 July 2014

Academic Editor: Chuanyi Wang

Copyright (C) 2014 Tianxing Li et al. This is an open access article distributed under the Creative Commons Attribution License, which permits unrestricted use, distribution, and reproduction in any medium, provided the original work is properly cited.

Quantum dot-sensitized solar cells (QDSSCs) have received extensive attention in recent years due to their higher theoretical conversion efficiency and lower production costs. However, the photoelectric conversion efficiency of QDSSCs is still lower than the DSSCs because of the severe recombination of electrons of quantum dots conduction band. In order to improve the photoelectric conversion efficiency of QDSSCs, impurity element $\mathrm{Mn}^{2+}$ is doped into the precursor solution of cadmium sulfide (CdS). By optimizing the experimental parameters, the photoelectric conversion efficiency of QDSSCs can be greatly improved. For the deposition of a fixed number of six times, the photoelectric conversion efficiency shows the maximum value (1.51\%) at the doped ratio of $1: 10$

\section{Introduction}

Quantum dot-sensitized solar cells (QDSSCs) have been recently drawing great attention due to the characteristics of quantum dots (QDs), such as high absorption coefficient, tunable band gap, and multiple exciton generation (MEG) effect [1-4]. However, its photoelectric conversion efficiency is still low compared to the theoretical value. The main factors limiting the efficiency of QDSSCs include the carriers recombination with redox couple on the semiconductor interface, a slower rate of hole transport, and the properties of the electrode. Recently, many efforts on the improvement of quantum dots (QDs), electrolyte, and electrode have made quite a lot of progress [5-7]. Among those researches doping optically active transition metal ions, such as $\mathrm{Mn}$, $\mathrm{Mg}, \mathrm{Co}, \mathrm{Cu}$, and $\mathrm{In}$, has achieved obvious improvement in the photoelectric conversion efficiency of QDSSCs [8-12]. The doped system modifies the electronic and photophysical properties of QDs [13]. In addition, it is also possible to tune the optical and electronic properties of semiconductor nanocrystals by controlling the type of dopant [14]. Very recently, Santra and Kamat fabricated Mn-doped-CdS/CdSe quantum dot solar cells and yielded the efficiency (5.42\%) for the QDSSCs [8]. And, the next year, Lee et al. reported on a $\mathrm{PbS}: \mathrm{Hg} \mathrm{QD}$-sensitized solar cells with an extremely high photocurrent density $\left(38 \mathrm{~mA} / \mathrm{cm}^{2}\right)$ [15].

CdS, as an important II-VI semiconductor compound, with the band gap of $2.42 \mathrm{eV}$ at room temperature [16], has good optical absorption properties in the visible region. Simultaneously, it has a large extinction coefficient and photochemical stability. Moreover, CdS quantum dots of different sizes can be synthesized to achieve broad spectral absorption through the relationship between the particle size and energy level of QDs. Therefore, the CdS quantum dots became a favorite QDs material for many researchers [17].

By the way of doping $\mathrm{Mn}$ atoms into CdS quantum dots, we can further regulate the properties of quantum dots for expanding the range of visible light absorption and improve the stability of cells $[18,19]$.

In this paper, we introduced impurity element $\mathrm{Mn}^{2+}$ into the precursor solution of cadmium sulfide (CdS). And Mn-doped-CdS QDs have been in situ deposited onto $\mathrm{TiO}_{2}$ 


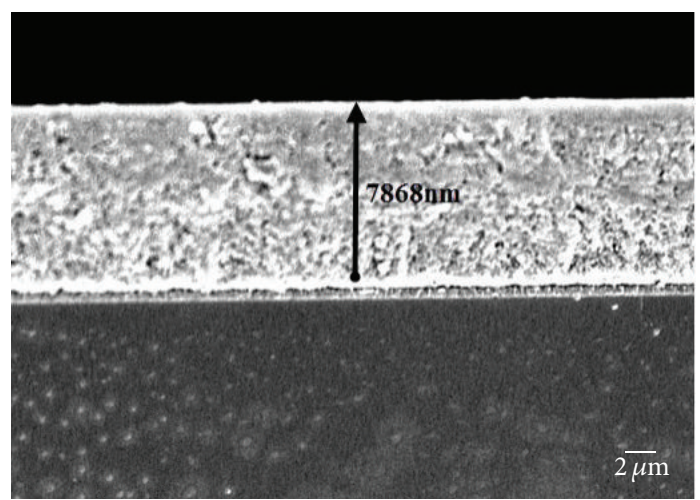

(a)

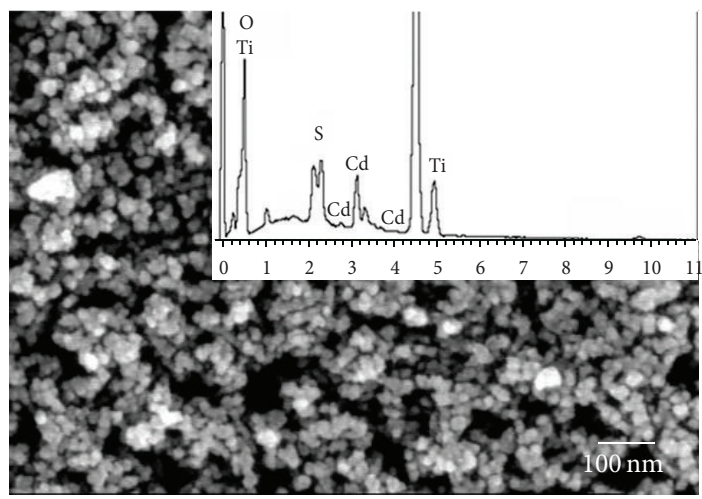

(c)

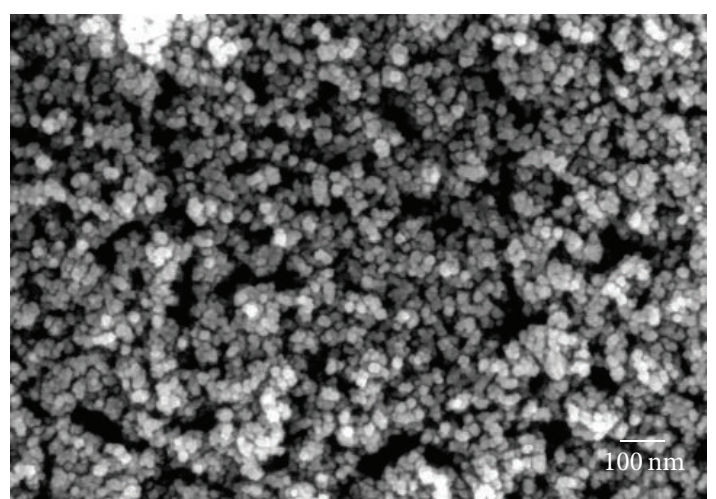

(b)

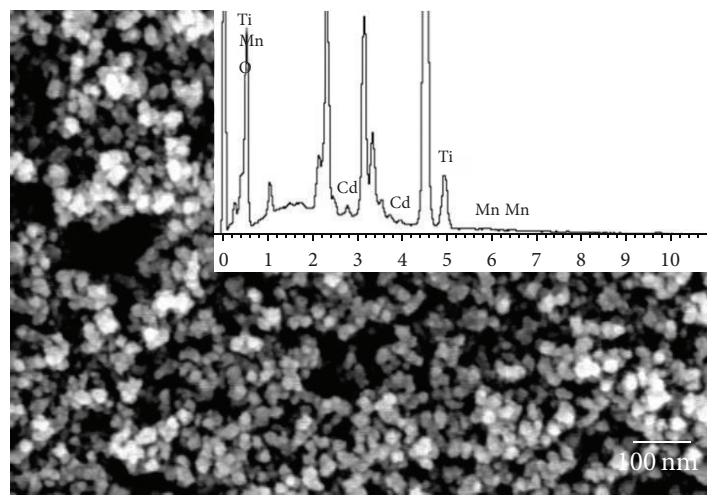

(d)

FIGURE 1: SEM images of (a) cross section of Mn-doped-CdS deposition of $\mathrm{TiO}_{2}$ photoanode; (b) pure $\mathrm{TiO}_{2}$ mesoporous film surface; (c) the surface of $\mathrm{TiO}_{2}$ mesoporous film sensitized by CdS quantum dots; and (d) the surface of $\mathrm{TiO}_{2}$ mesoporous film sensitized by Mn-doped-CdS quantum dots. Among them, the inset in the following two graphs is the corresponding EDS spectrum.

mesoporous substrates by the successive ionic layer adsorption and reaction (SILAR). Then, we assembled Mn-doped$\mathrm{CdS}$ quantum dot-sensitized solar cells with the structure of photoanode $\backslash$ polysulfide electrolyte $\backslash \mathrm{Pt}$ counter and incidentally discussed the impact of doping. We emphatically analyzed the effect of doped ratio and SILAR cycles on the properties of QDSSCs. At last, the power conversion efficiency of Mn-doped-CdS QDSSCs showed 1.51\% under air mass (AM) 1.5 condition $\left(100 \mathrm{~mW} / \mathrm{cm}^{2}\right)$ with the optimized parameters (the doped ratio of $\mathrm{Mn}$ : CdS fixed on $1: 10$ and the six cycles of SILAR) obtained by experiment. Although the conversion efficiency is still low, it is much higher than the undoped CdS QDSSCs. And, with increased doping ratio, the efficiency had no further improvement but beginning to reduce.

\section{Experimental}

The $\mathrm{TiO}_{2}$ nanoparticles are uniformly coated on the surface of the FTO (fluorine-doped tin oxide) by screen printing method and then annealed at $450^{\circ} \mathrm{C}$ for $30 \mathrm{~min}$. And the counter electrode is prepared with $\mathrm{Pt}$ which is obtained from the thermal decomposition of chloroplatinic acid. Like the preparation of $\mathrm{TiO}_{2}$ photoanode, the counter electrode has also been annealed at $450^{\circ} \mathrm{C}$ for $30 \mathrm{~min}$. A mixed methanol and deionized water solution $(1: 1)$ of $\mathrm{Na}_{2} \mathrm{~S}(0.5 \mathrm{M}), \mathrm{S}(2 \mathrm{M})$, and $\mathrm{KCl}(0.2 \mathrm{M})$ is used as the polysulfide electrolyte.

Here, in this work, we used $\mathrm{C}_{4} \mathrm{H}_{6} \mathrm{MnO}_{4}$ which contains impurity elements incorporated into the precursor solution by doping $\mathrm{Mn}$ in situ for the fabrication of Mn-doped-CdS QDs on the $\mathrm{TiO}_{2}$ photoanode. In brief, specific concentration of the $\mathrm{C}_{4} \mathrm{H}_{6} \mathrm{MnO}_{4}$ was mixed with $\mathrm{Cd}\left(\mathrm{NO}_{3}\right)_{2}(0.1 \mathrm{M})$ in the ethanol solution as cation source. $\mathrm{Na}_{2} \mathrm{~S}(0.1 \mathrm{M})$ in methanol was used as anion source. The prepared $\mathrm{TiO}_{2}$ photoanode was immersed in the mixed ethanol solution of $\mathrm{C}_{4} \mathrm{H}_{6} \mathrm{MnO}_{4}$ and $\mathrm{Cd}\left(\mathrm{NO}_{3}\right)_{2}$ for $5 \mathrm{~min}$, followed by rinsing with ethanol and drying with nitrogen. Subsequently, the $\mathrm{TiO}_{2}$ photoanode was dipped into $\mathrm{Na}_{2} \mathrm{~S}(0.1 \mathrm{M})$ methanol solution for $5 \mathrm{~min}$ at $30^{\circ} \mathrm{C}$. And, then, one cycle of SILAR has been completed. During the experiment, to meet the research needs, we changed the ratio of molar concentration of $\mathrm{C}_{4} \mathrm{H}_{6} \mathrm{MnO}_{4}$ in the cation source solution (i.e., doping ratio of $\mathrm{Mn}$-doped$\mathrm{CdS})$.

\section{Result and Discussion}

Figure 1(a) shows scanning electron micrograph (SEM) of the $\mathrm{TiO}_{2}$ film deposited by Mn-doped-CdS (1:10) with a thickness of $7.87 \mu \mathrm{m}$. Figure $1(\mathrm{~d})$ suggests that the vertical 


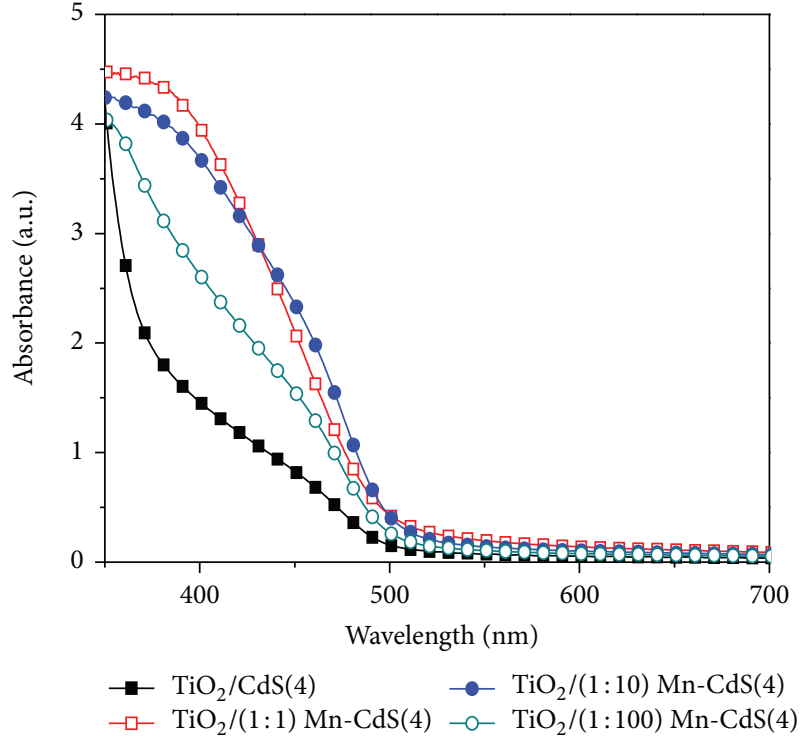

(a)

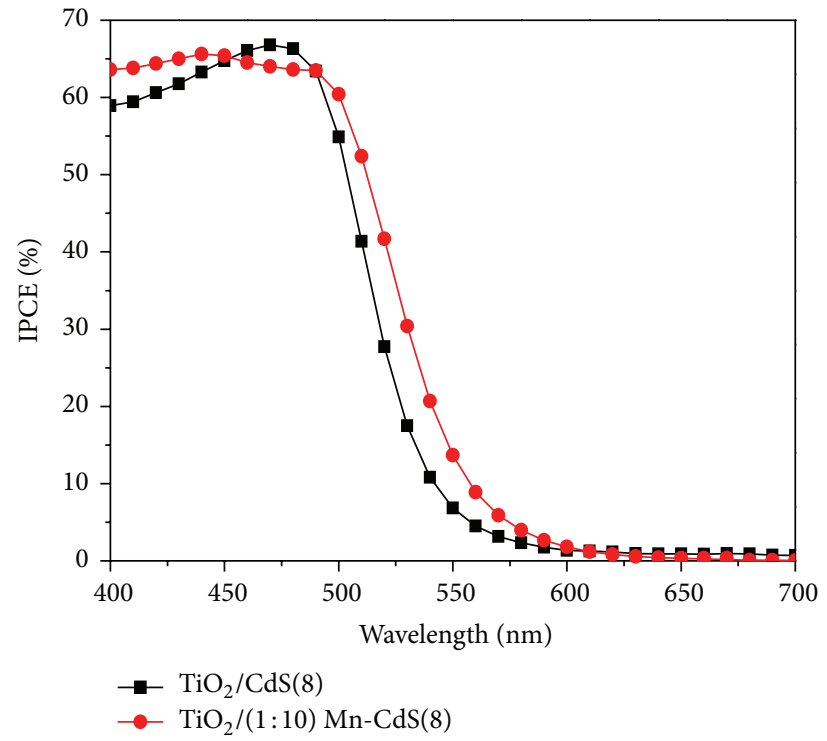

(b)

FIGURE 2: (a) UV-Vis absorption spectra and (b) IPCE spectra of undoped CdS QDs and different doped ratio of Mn-doped-CdS QDs.

morphology of $\mathrm{TiO}_{2}$ photoanode is deposited by Mn-dopedCdS. There is no obvious change of the vertical morphology of the film between (b) and (c) images. It is proved that the QDs are small enough for the interspace of $\mathrm{TiO}_{2}$ mesoporous film. And the existence of those interspaces makes sure of the full penetration of electrolyte. For the existence of quantum dots is unknown, the EDS spectrum is shown in inset of Figures 1(c) and $1(\mathrm{~d})$. And the comparison between two spectrums demonstrated that the $\mathrm{Mn}$ is existent in the film.

Figure 2(a) shows the UV-Vis absorption spectra of different working electrodes based on Mn concentration. Compared to the undoped one; the Mn-doped-CdS show the obvious red shift in the UV-Vis absorption spectra. The initial response in the wavelength of undoped one, like the Mn-doped-CdS QDs, is approximated to be $500 \mathrm{~nm}$. But the spectral response range has been extended after deposition. This phenomenon is due to the introduction of midgap states between the conduction band and the valence band of $\mathrm{TiO}_{2}$ QDs by Mn doping, which could provide electron in the long wavelength region of the spectrum. And the complementary in the spectral responses can enhance photoelectric conversion efficiency of QDSSCs. The absorption spectra of Mn$\mathrm{CdS}(1: 1)$ is very similar to Mn-CdS $(1: 10)$, which is red shift compared to the sample of Mn-CdS $(1: 100)$.

The incident photon-to-electron conversion efficiency (IPCE) spectra of the doped and undoped QDSSCs at different incident light wavelengths were shown in Figure 2(b). The maximum IPCE value of two samples is about $67 \%$. However, the spectral response range of $\mathrm{Mn}$-doped-CdS QDSSCs is wider than the undoped one. This is due to the fact the introduction of impurities of $\mathrm{Mn}$ enhances the spectral response of the CdS QDSSCs, so that more electrons transferred to the external circuit and the generation of dark
TABLE 1: Different photovoltaic parameters for different samples.

\begin{tabular}{lcccc}
\hline Sample & $J_{\text {sc }}\left(\mathrm{mA} / \mathrm{cm}^{2}\right)$ & $V_{\text {oc }}(\mathrm{mV})$ & $\mathrm{FF}$ & $\eta(\%)$ \\
\hline $\mathrm{TiO}_{2} / \mathrm{CdS}(4)$ & 4.29 & 474 & 0.35 & 0.71 \\
$\mathrm{TiO}_{2} /(1: 1) \mathrm{Mn}-\mathrm{CdS}(4)$ & 4.13 & 482 & 0.44 & 0.88 \\
$\mathrm{TiO}_{2} /(1: 10) \mathrm{Mn}-\mathrm{CdS}(4)$ & 5.88 & 514 & 0.41 & 1.24 \\
$\mathrm{TiO}_{2} /(1: 100) \mathrm{Mn}-\mathrm{CdS}(4)$ & 4.82 & 438 & 0.33 & 0.70 \\
\hline
\end{tabular}

TABLE 2: ICP-OES test data of Mn-doped-CdS.

\begin{tabular}{lccccc}
\hline Sample & $\begin{array}{c}\mathrm{Cd} \\
(\mu \mathrm{g})\end{array}$ & $\begin{array}{c}\mathrm{Mn} \\
(\mu \mathrm{g})\end{array}$ & $\begin{array}{c}\mathrm{Cd} \\
\left(10^{-6} \mathrm{~mol}\right)\end{array}$ & $\begin{array}{c}\text { Mn } \\
\left(10^{-6} \mathrm{~mol}\right)\end{array}$ & $\begin{array}{c}\text { Molar ratio of } \\
\mathrm{Mn}\end{array}$ \\
\hline Mn-CdS & 1045 & 5.373 & 9.297 & 0.098 & $1.054 \%$ \\
\hline
\end{tabular}

current is also suppressed, which is consistent with the UVvisible absorption spectra of samples.

The $J-V$ characteristics of those QDSSCs samples based on diverse doped ratio are presented in Figure 3, with 4 cycles of SILAR. Simultaneously, the corresponding performance parameters of those samples are presented in Table 1.

As can be seen from the chart, Mn-doped-CdS QDSSCs exhibited considerable increment close to $58 \%$ (from $0.71 \%$ to $1.24 \%$ ) in the power conversion efficiency, compared to the corresponding undoped sample. The highest overall power conversion efficiency (1.24\%) was achieved with the most optimized Mn doped amount. And the actual Mn concentration, applied on an inductively coupled plasma optical emission spectroscopy (ICP-OES), shown in Table 2, was found to be $1.054 \%$ in the CdS film. Higher Mn concentration might damage the performance. Therefore, as the proportion of $\mathrm{Mn}$ doping gradually reduced, the $J_{\mathrm{sc}}$ increased from $4.13 \mathrm{~mA} / \mathrm{cm}^{2}(1: 1)$ to $5.88 \mathrm{~mA} / \mathrm{cm}^{2}(1: 10)$. But when the 


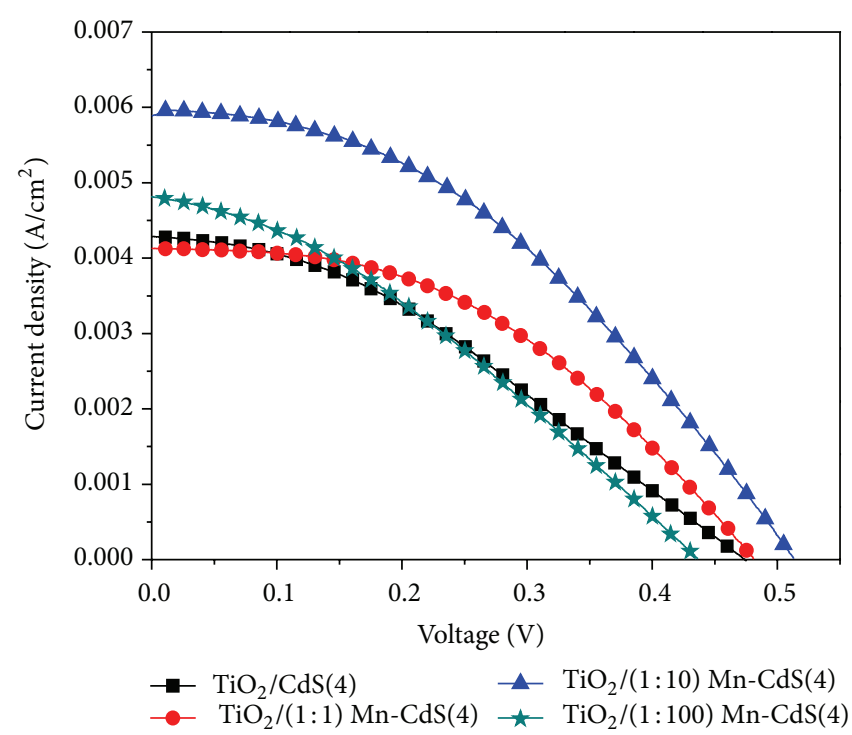

FIgURE 3: The $J-V$ characteristics of different sample based on the doped ratio of Mn doping.

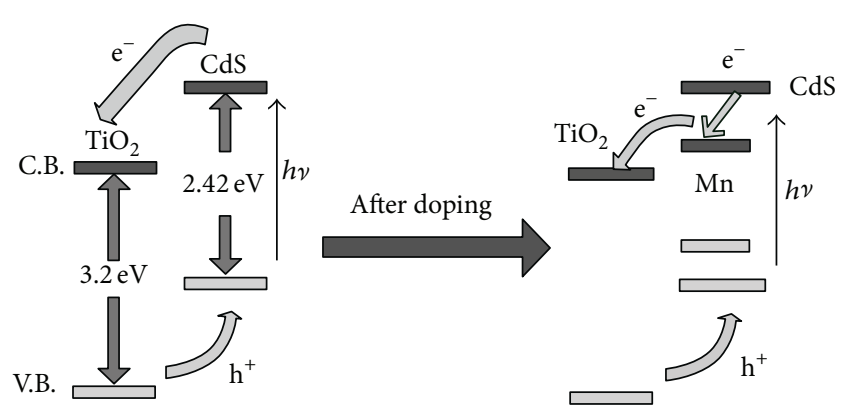

FIGURE 4: The $\mathrm{TiO}_{2} / \mathrm{CdS}$ energy level structure diagram before and after doping.

concentration continues to decrease, the performance of cells is declined. Meanwhile, the fill factor (FF) remained stable.

The higher $J_{\mathrm{sc}}$ of the Mn-doped-CdS films is mainly attributed to the midgap states created by Mn doping, which not only enhances the capture for electrons and slows the speed of electrons transport but also screens partly the charge recombination with the hole and polysulfide electrolyte after oxidation. Indeed, the improved photovoltage in the QDSSCs with doped semiconductor films indicates that Mn-doping assists in electron accumulation within the QDs layers, thus shifting the Fermi level to more negative potentials and increasing the conduction band of CdS. As shown in Figure 4, the Fermi energy is adjusted to an even lower electric potential, due to the promotion of electron collection by doping.

In addition, the $J_{\mathrm{sc}}$ of the CdS QDSSCs will be improved by the Mn doping with the relatively high doped ratio. However, a large number of recombination centers, which have been introduced along with the Mn ions doped on the CdS QDs, are an unfavorable factor for the performance of solar cells. The enhancement for the $J_{\text {sc }}$ by Mn doping increased firstly when the doping ratio is decreased. In contrast, as
TABLE 3: Different photovoltaic parameters for different samples.

\begin{tabular}{lcccc}
\hline SILAR cycles & $J_{\text {sc }}\left(\mathrm{mA} / \mathrm{cm}^{2}\right)$ & $V_{\text {oc }}(\mathrm{mV})$ & $\mathrm{FF}$ & $\eta(\%)$ \\
\hline $\mathrm{TiO}_{2} /(1: 10) \mathrm{Mn}-\mathrm{CdS}(2)$ & 3.67 & 471 & 0.38 & 0.65 \\
$\mathrm{TiO}_{2} /(1: 10) \mathrm{Mn}-\mathrm{CdS}(4)$ & 6.02 & 501 & 0.31 & 0.92 \\
$\mathrm{TiO}_{2} /(1: 10) \mathrm{Mn}-\mathrm{CdS}(6)$ & 7.90 & 536 & 0.36 & 1.51 \\
$\mathrm{TiO}_{2} /(1: 10) \mathrm{Mn}-\mathrm{CdS}(8)$ & 7.13 & 592 & 0.29 & 1.21 \\
\hline
\end{tabular}

the doped ratio decreased, the enhancement is weakened. And the crystal defects caused by Mn doping still exist, so that the short-circuit current density and photoelectric conversion efficiency began to decline. In this experiment, we just changed the ratio of molar concentration of $\mathrm{C}_{4} \mathrm{H}_{6} \mathrm{MnO}_{4}$ and $\mathrm{Cd}\left(\mathrm{NO}_{3}\right)_{2}$. It has little effect on the fill factor, so there is no significant change about it.

Based on the above discussion, the doped ratio is fixed on 1:10 as the most optimized Mn-doped concentration. Figure 5(a) gives the UV-Vis absorption spectra of four samples based on different SILAR cycles. It shows that the exciton absorption peak of those samples moved in a direction toward the long wavelength. And there is a sample exciton absorption peak at about $680 \mathrm{~nm}$, which means manganese sulfur compounds may be formed during the deposition.

The IPCE recorded at different SILAR cycles for QDSC that employ three different photoactive semiconductor electrodes is shown in Figure 5(b). The overall photocurrent response matching the absorption features also increases along with the repetition of SILAR cycles.

The $J-V$ characteristics and the corresponding performance parameters of those Mn-doped-CdS QDSSCs are presented in Figure 6 and Table 3. Obviously, as the times of SILAR cycles increased, there was a clearly different performance from the $J_{\mathrm{sc}}, \mathrm{FF}$, and $V_{\mathrm{oc}}$. The best performance is obtained with the sample of 6 cycles of SILAR. When we 


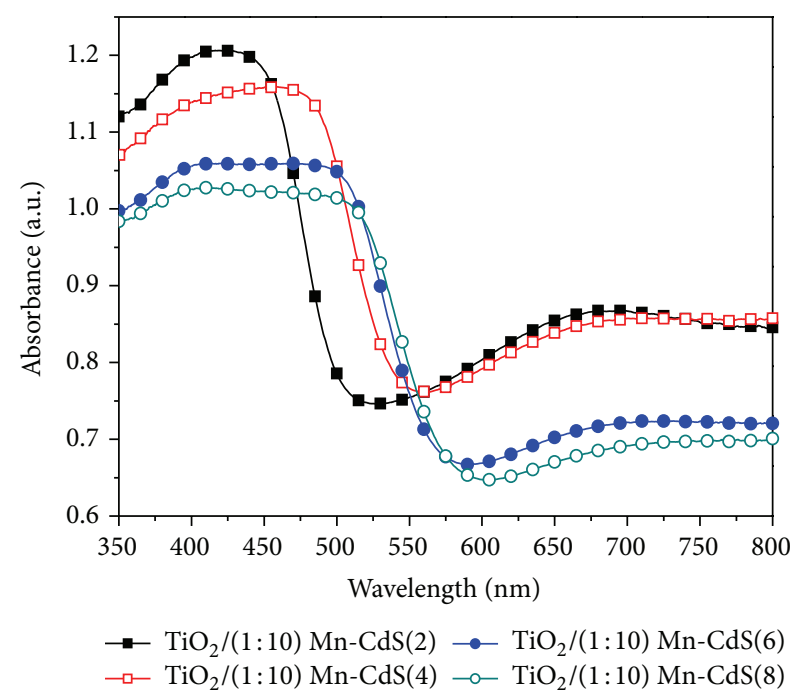

(a)

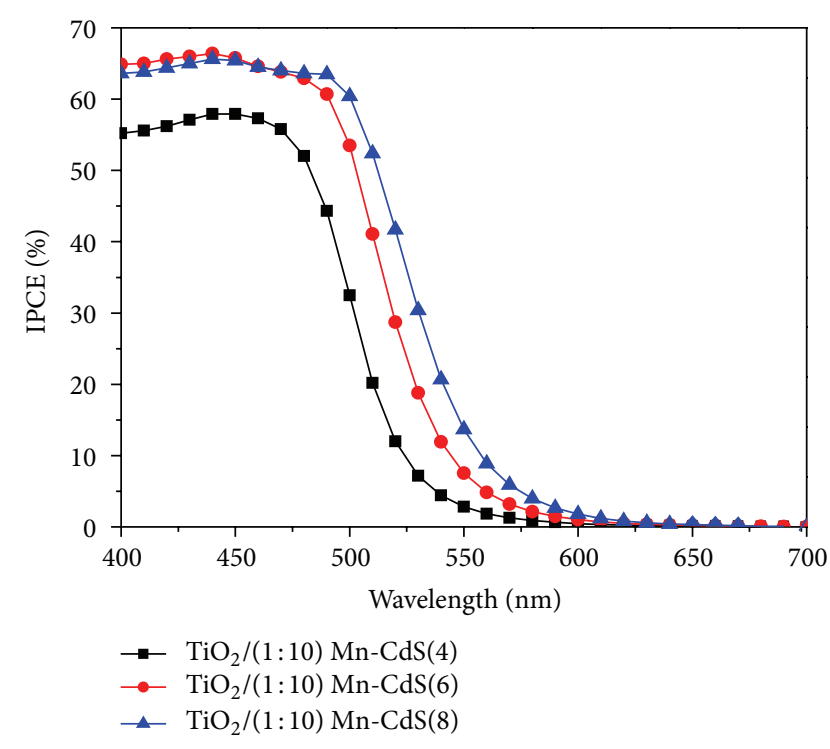

(b)

FIGURE 5: (a) UV-Vis absorption spectra and (b) IPCE spectra of mesoscopic $\mathrm{TiO}_{2}$ photoanode deposited by different SILAR cycles of Mndoped-CdS QDs.

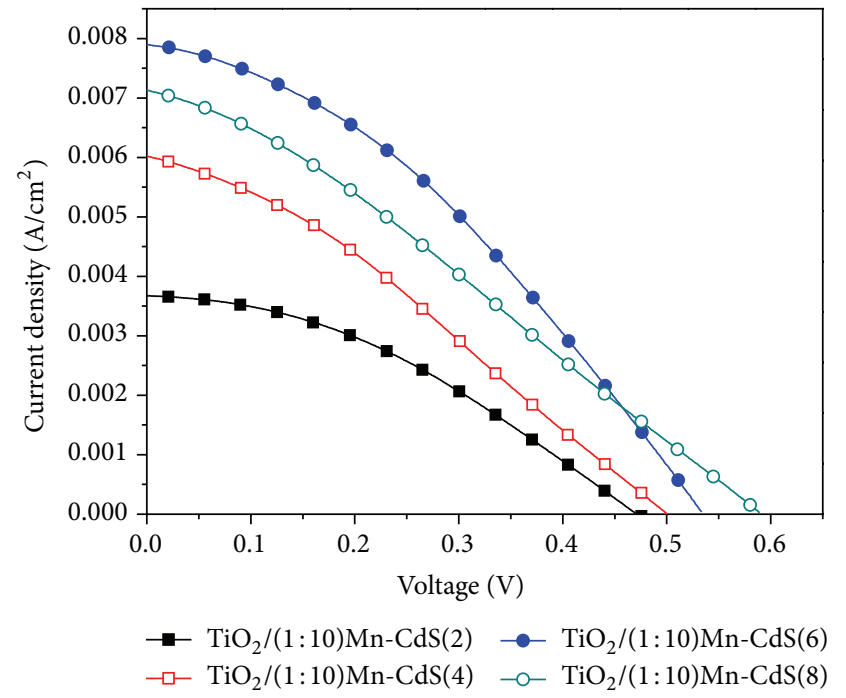

FIGURE 6: The $J-V$ characteristics of different sample based on SILAR cycles.

repeat the process of deposition by Mn-doped-CdS QDs, more QDs will be generated on the mesoscopic $\mathrm{TiO}_{2}$ film, leading to the accumulation of photo-generated electron. Therefore, the quasi-Fermi level of Mn-doped-CdS QDs is shifted to more negative potentials like the effect of $\mathrm{Mn}$ doping. But excessive deposition of QDs caused stoppage of interspace of the mesoscopic $\mathrm{TiO}_{2}$ film and severe recombination of electrons. So the $J_{\mathrm{sc}}$ is enhanced at first but got down finally. In contrast, because the conduction band of QDs increased with the repetition of SILAR cycles, the $V_{\text {oc }}$ keep increasing.

\section{Conclusions}

In summary, the doping of CdS films with Mn has enabled us to achieve a significant improvement as compared to undoped films. After the optimization of experimental parameters, the photoelectric conversion efficiency of $\mathrm{Mn}$ doped-CdS QDSSCs shows the maximum value (1.51\%). Although the performance is still lower than the expected value, it gives us another optional approach for making QDSSCs competitive.

\section{Conflict of Interests}

The authors declare that there is no conflict of interests regarding the publication of this paper.

\section{Acknowledgments}

This work was partially supported by the Key Project of Beijing Natural Science Foundation (3131001), the Key Project of Natural Science Foundation of China (91233201 and 61376057), the Key Project of Beijing Education Committee Science \& Technology Plan (KZ201211232040), the State 863 Plan of MOST of China (2011AA050527), the Beijing National Laboratory for Molecular Sciences (BNLMS2012-21), the State Key Laboratory of Solid State Microstructures of Nanjing University (M27019), the State Key Laboratory for Integrated Optoelectronics of Institute of Semiconductors of CAS (IOSKL2012KF11), the State Key Laboratory for New Ceramic and Fine Processing of Tsinghua University (KF1210), the Key Laboratory for Renewable Energy and Gas Hydrate of Chinese Academy of Sciences (y207ka1001), the Beijing Key Laboratory for Sensors of BISTU (KF20131077208), and the 
Beijing Key Laboratory for photoelectrical measurement of BISTU (GDKF2013005).

\section{References}

[1] A. J. Nozik, M. C. Beard, J. M. Luther, M. Law, R. J. Ellingson, and J. C. Johnson, "Semiconductor quantum dots and quantum dot arrays and applications of multiple exciton generation to third-generation photovoltaic solar cells," Chemical Reviews, vol. 110, no. 11, pp. 6873-6890, 2010.

[2] J. B. Sambur, T. Novet, and B. A. Parkinson, "Multiple exciton collection in a sensitized photovoltaic system," Science, vol. 330, pp. 63-66, 2010.

[3] P. V. Kamat, "Quantum dot solar cells. Semiconductor nanocrystals as light harvesters," Journal of Physical Chemistry C, vol. 112, no. 48, pp. 18737-18753, 2008.

[4] J. Tang, "Colloidal-quantum-dot photovoltaics using atomicligand passivation," Nature Materials, vol. 10, pp. 765-771, 2011.

[5] L. Li, X. C. Yang, J. J. Gao et al., "Highly efficient CdS quantum dot-sensitized solar cells based on a modified polysulfide electrolyte," Journal of the American Chemical Society, vol. 133, no. 22, pp. 8458-8460, 2011.

[6] Q. Shen, A. Yamada, S. Tamura, and T. Toyoda, "CdSe quantum dot-sensitized solar cell employing $\mathrm{TiO}_{2}$ nanotube workingelectrode and $\mathrm{Cu}_{2} \mathrm{~S}$ counter-electrode," Applied Physics Letters, vol. 97, no. 12, Article ID 123107, 2010.

[7] G. S. Paul, J. H. Kim, M. S. Kim, K. Do, J. Ko, and J. Yu, "Different hierarchical nanostructured carbons as counter electrodes for Cds quantum dot solar cells," ACS Applied Materials and Interfaces, vol. 4, no. 1, pp. 375-381, 2012.

[8] P. K. Santra and P. V. Kamat, "Mn-doped quantum dot sensitized solar cells: a strategy to boost efficiency over 5\%," Journal of the American Chemical Society, vol. 134, no. 5, pp. 2508-2511, 2012.

[9] W. Lee, W.-C. Kwak, S. K. Min et al., "Spectral broadening in quantum dots-sensitized photoelectrochemical solar cells based on CdSe and Mg-doped CdSe nanocrystals," Electrochemistry Communications, vol. 10, no. 11, pp. 1699-1702, 2008.

[10] X. P. Zou, S. He, G. Teng, and C. Zhao, "Performance study of CdS/Co-doped-CdSe quantum dot Sensitized solar cells," Journal of Nanomaterials, vol. 2014, Article ID 818160, 6 pages, 2014.

[11] Y. Y. Gao, Z. B. Huang, and X. Zou, "Doped heterojunction used in quantum dot sensitized solar cell," International Journal of Photoenergy, vol. 2014, Article ID 179289, 7 pages, 2014.

[12] L. Li, X. P. Zou, H. Zhou, and G. Teng, "Cu-doped-CdS/Indoped-CdS cosensitized quantum dot solar cells," Journal of Nanomaterials, vol. 2014, Article ID 314386, 8 pages, 2014.

[13] N. S. Karan, D. D. Sarma, R. M. Kadam, and N. Pradhan, "Doping transition metal ( $\mathrm{Mn}$ or $\mathrm{Cu})$ ions in semiconductor nanocrystals," Journal of Physical Chemistry Letters, vol. 1, no. 19, pp. 2863-2866, 2010.

[14] S. Jana, B. B. Srivastava, and N. J. Pradhan, "Correlation of dopant states and host bandgap in dual-doped semiconductor nanocrystals," The Journal of Physical Chemistry Letters, vol. 2, pp. 1747-1752, 2011.

[15] J. W. Lee, D. Y. Son, T. K. Ahn et al., "Quantum-dot-sensitized solar cell with unprecedentedly high photocurrent," Scientific Reports, vol. 3, article 1050, 2013.

[16] M. Grätzel, "Review article photoelectrochemical cells," Nature, vol. 414, no. 15, pp. 338-344, 2001.
[17] J. Yasuaki, S. Naya, and H. Tada, "Quantum-dot-sensitized solar cell using a photoanode prepared by in situ photodeposition of CdS on nanocrystalline $\mathrm{TiO}_{2}$ films," Journal of Physical Chemistry C, vol. 114, no. 39, pp. 16837-16842, 2010.

[18] D. S. Kim, Y. J. Cho, J. Park, J. Yoon, Y. Jo, and M. Jung, "(Mn, $\mathrm{Zn}$ ) Co-doped CdS nanowires," Journal of Physical Chemistry C, vol. 111, no. 29, pp. 10861-10868, 2007.

[19] B. Sambandam and P. T. Manoharan, "Davydov split PL emission and EPR correlation in $\beta$-mns layered cds nanorods," Journal of Physical Chemistry C, vol. 113, no. 22, pp. 9486-9496, 2009. 

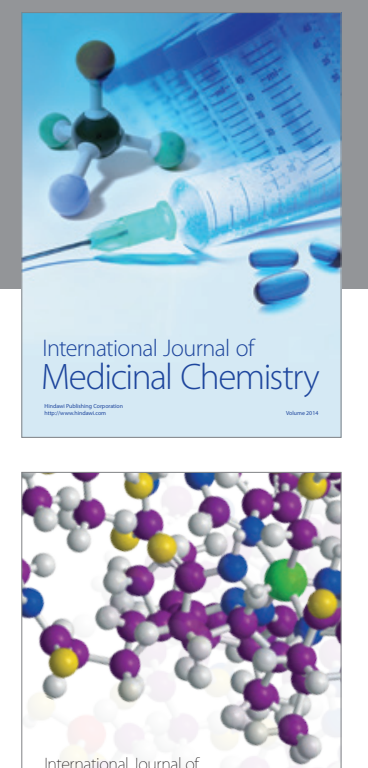

\section{Carbohydrate} Chemistry

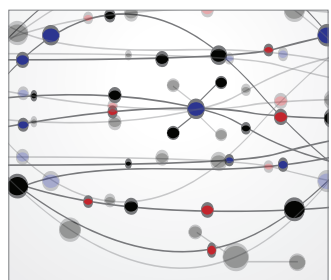

The Scientific World Journal
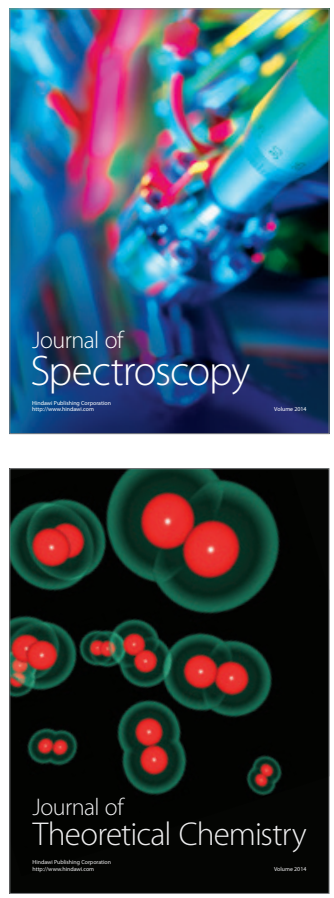
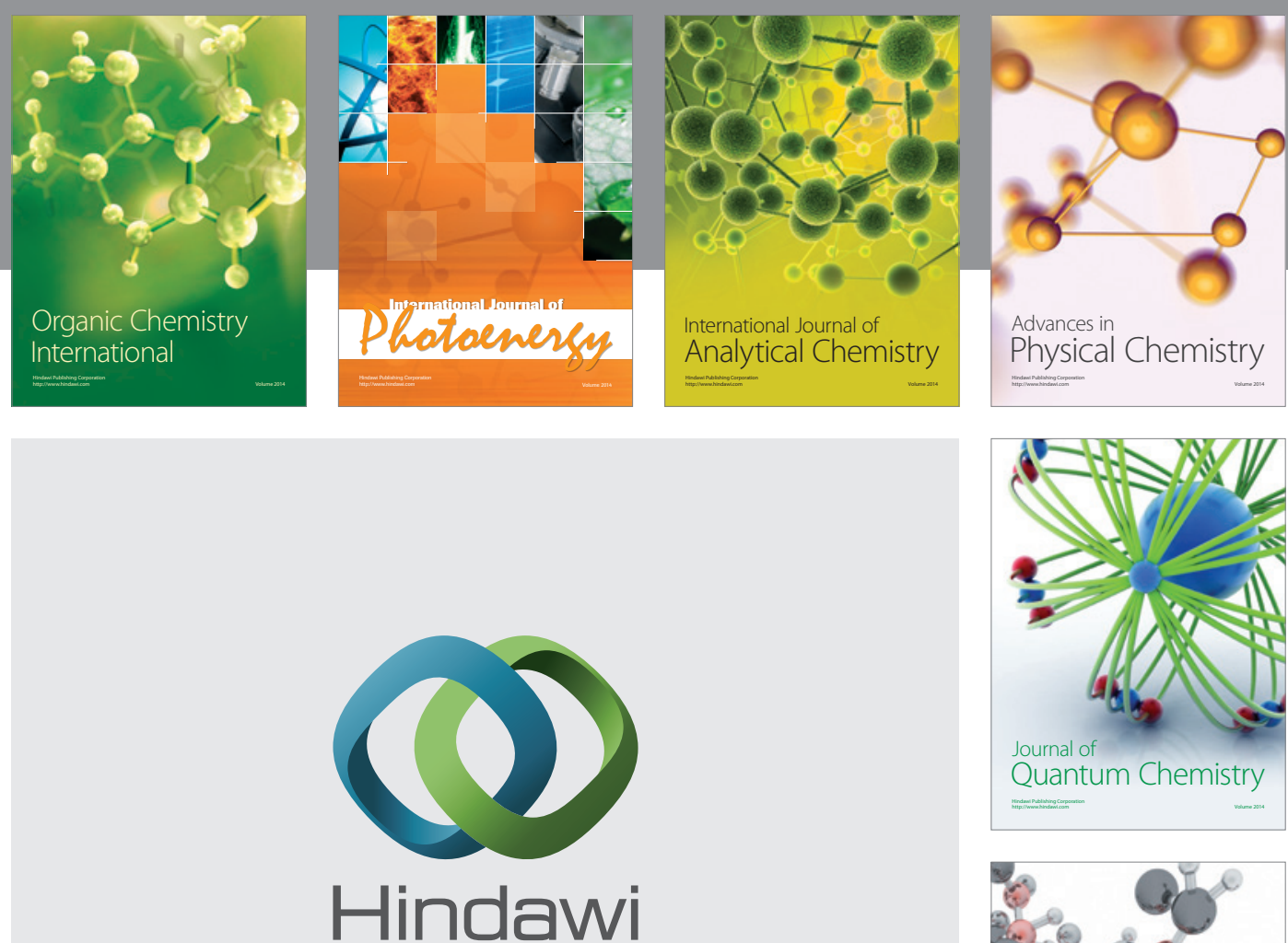

Submit your manuscripts at

http://www.hindawi.com

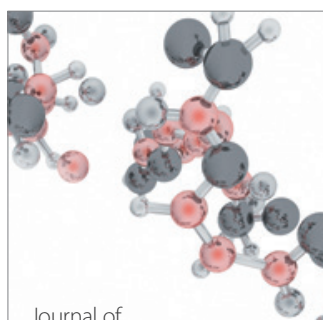

Analytical Methods

in Chemistry

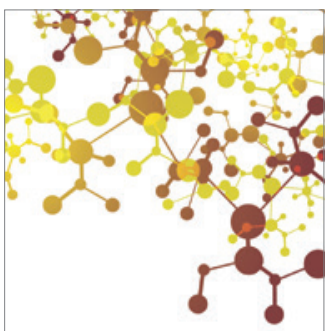

Journal of

Applied Chemistry

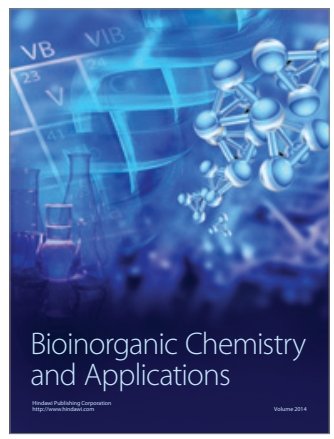

Inorganic Chemistry
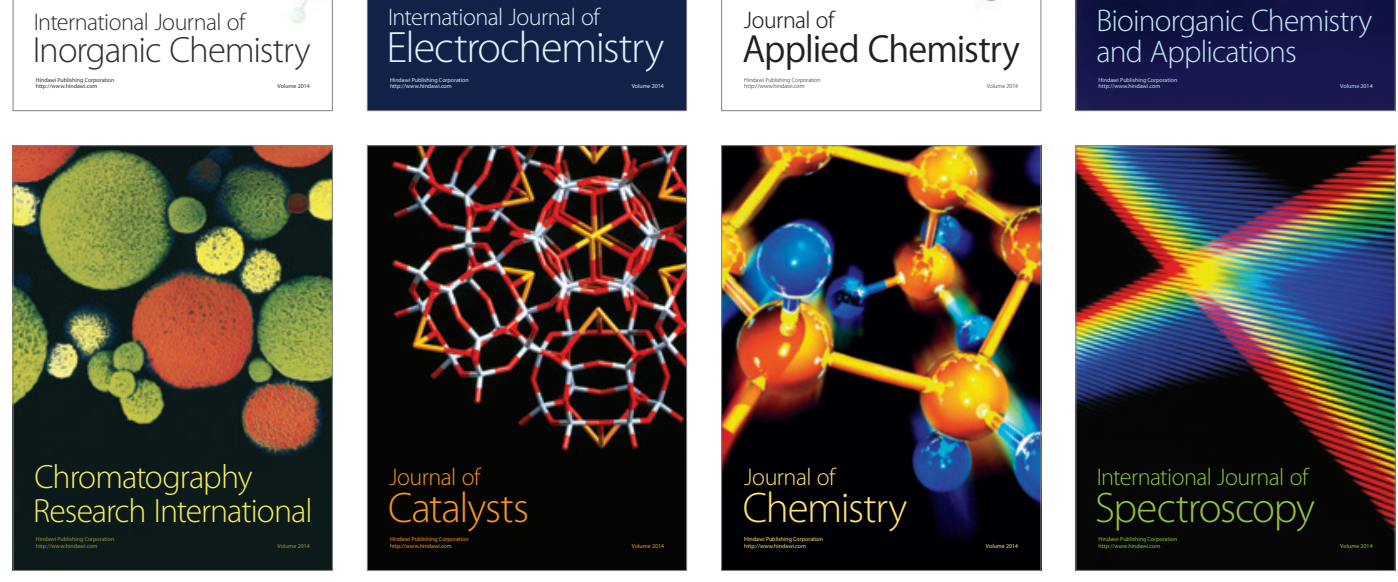